generations of the South Asians of London, in whether they continue to show a genetically determined pattern of cardiovascular disease and diabetes or, being born of more affluent mothers, in whether their disease incidence comes to conform to that of other racial groups born in Britain.

More work needs to be done, and particularly in countries free of the confounding effects of the social class structure of early twentieth century Britain, before the Barker hypothesis can achieve universal acceptance. It certainly should not be allowed to justify a fatalistic attitude to lifestyle improvements in adult life. If correct, however, it may lead to better targeting of lifestyle interventions, particularly in terms of diet, to those members of the population for whom they are crucial - while the rest of us will be able to gorge ourselves in peace.

\title{
References
}

Kuh, D. and Davey Smith, G. 1993. When is mortality risk determined? Historical insights into a current debate. Social History of Medicine, 6, $101-123$.

McKeigue, P. M., Shah, B. and Marmot, M. G. 1991. Relation of central obesity and insulin resistance with high diabetes prevalence and cardiovascular risk in South Asians. Lancet, 337, 382-386.

Neel, J. V. 1962. Diabetes mellitus: a 'thrifty' genotype rendered detrimental by 'progress'? American Journal of Human Genetics, 14, 353-362.

Department of Clinical Geratology, Radcliffe Infirmary, Oxford

\section{Social Policy}

Lorna Warren

Preparing these abstracts in 1993, I approached potential articles for what they might reveal about the position of older people in society and about their relationship with other generations. The three articles which I have chosen are linked by the themes of needs, resources and empowerment.

Andrew Bebbington and Bleddyn Davies, Efficient targeting of community care: the case of the home help service, Journal of Social Policy, 2, 3 (1993) 373-391.

1993 was not only the European Year of Older People and Solidarity Between the Generations, it also saw the full implementation of the I 990 National Health Service and Community Care Act. As a group, older people constitute one of the major users of community care, of 
which, as the authors point out, the home help service is a cornerstone. It is with timeliness, therefore, that Andrew Bebbington and Bleddyn Davies have produced their analysis of the targeting of domiciliary care with its conclusions about the effectiveness of the service and implications for care management. Their article, in fact, is a sequel to an earlier I 993 paper and, through the use of General Household Survey data, reviews the effects of new policies aimed at concentrating the home help service on those in greatest need, being responsive to the needs of carers, and exploiting the potential for the self-financing of care. Target efficiency is taken as referring to the equity and efficiency with which older people are recruited and retained as service users. Adding a new target group to the original three, the authors offer four definitions of need which focus on extent of disability, and availability of support and resources. Efficiency is measured in terms of the proportion of those in priority who receive the service (horizontal target efficiency) and the proportion of recipients (or resources) which satisfy the criteria defining need (vertical target need), as well as the ratio between these dimensions.

The findings are perhaps clearer than the method. Overall, there was an increase in the receipt of home help over the period studied but Bebbington and Davies question the evenness with which it has been distributed. For example, the home help service has not become better targeted but instead has gone to people outside their definitions of those in priority need: people aged over 80 years are $2 \frac{1}{2}$ times as likely to get services as people under 80 at similar levels of disability. There is evidence that services are becoming more equitable allocated between broad regions of England but not between men and women: the increase in home help provision between 1980 and 1985 went almost entirely to old men living alone.

On the other hand, the allocation of services to women is more closely linked to disability, so that disabled men are actually worse served than disabled women. In terms of married couple households, help is more likely to be given where it is the wife rather than the husband who is disabled. In other words, male carers are supported more readily than female carers. In addition to informal support, the availability of resources also influences the allocation of home helps, adding further to the discrimination against older women since, as a group, they are relatively poorer than men.

Theses findings confirm the existence of structural inequalities relating to a number of widely-held myths influencing service provision, including the belief that risk automatically increases with age, that older men are unfamiliar with domestic tasks, and that (at all ages) women are more capable carers than men. Bleddyn and Davies call for 
the sharpening of targeting criteria. The major reason for government interest in improving efficiency is undoubtedly to do with cost, but it can be no bad thing if ageist stereotypes are broken down in the process. One way to begin to tackle this goal might be through the use of questionnaires, the subject of investigation in the second paper.

Christopher Dowrick, Self-assessment by elderly people - a means of identifying unmet need in primary care, Health and Social Care, 1, (1993), 289-296.

Motivated by a concern for the 'iceberg' of undiagnosed depression, dementia and emotional and social needs amongst older people revealed, in part, through the introduction of mandatory health screening for people aged over 75-Dowrick set out to explore the usefulness of a self-completed postal questionnaire. This instrument, a modification of an 18 point schedule produced by Bowns et al (1991), was sent to all patients aged $75+$ years $(498)$ belonging to a general practice in Liverpool. In addition to standard items covering social support, disability and stresses and mood states, it contained two new questions, devised in discussion with a small group of older patients, which asked about recent contact with the primary care team and whether individuals thought it was necessary to them to see a doctor or nurse.

Dowrick achieved a high response rate of $84 \%$. The findings of the questionnaire itself are not particularly surprising. The majority of older people felt they had adequate social support, were able to cope with activities of daily living and were in good physical and mental health. Most had recently seen a GP or a nurse and did not feel the need to see one at present. However, there was a minority of older patients who saw themselves as having problems in three main areas: social isolation, bereavement and memory loss. Their records were checked and revealed a failure of the primary health care team to enquire about these problems and to focus instead on disability, illness and the notion of risk.

Dowrick warns against drawing inferences from results based on the new questionnaire items which have yet to be validated. He also states that some of the problems may be beyond the capacity of GPs and community nurses alone to address, and should be shared with other key bodies like the social services.

Dowrick is right to encourage co-operation between services and to call for a generally increased awareness of older people's concerns. But self-completed questionnaires remain a limited method of under- 
standing and responding to people's needs. For practical reasons not least, they ask only for basic information which reflects the professional concerns of the primary health care team. The discussion group aside, the involvement of older people is minimal and very much at a distance. Moreover, there is more than a whiff of patronage when the author writes of older people as asking for help 'appropriately' and as being capable of being 'relied upon' to assess their health correctly (p. 295): ultimately, the professional still knows best? The final paper addresses the issue of ageist stereotypes and calls for the involvement of older people at a much wider level and has clear implications for welfare issues.

Jay Ginn, Grey power: age-based organisations' response to structured inequalities, Critical Social Policy, 13, 2 (1993), 23-47.

Aspects of the previous articles suggest that professionals working in the field of social and health care operate in ways which are, generally, unconsciously ageist. It is Jay Ginn's contention that myths about older people are deliberately manipulated by others: specifically, those who wish to justify cuts in public pensions depict older people as threatening the viability of welfare states through their demands on resources. Solidarity between the generations seems a distant dream if the subsequent intergenerational war predicted by some commentators is to take place. Ginn points out the distinction between this kind of ageism, which she and Sarah Arber have referred to, using a somewhat more tempered term, as 'conflictual', and the 'passionate ageism' identified in the above articles, whereby older people are characterised as a social problem because of their supposed frailty, poverty and dependence.

On the other hand, both of these ageist attitudes produce the same result - that of conceptually isolating older people from the rest of society. And it is Ginn's aim both to understand and challenge this position. This she does in three ways. First, she queries the extent of influence and affluence of older people by noting the limited number of older people in important positions in society (those who hold such positions are typically white, male and middle class), raising the issue of elder abuse, indicating the lack of homogeneity amongst older people as a voting group, and revealing their low levels of income relative to the national average. She highlights the particular powerlessness of women and ethnic minority older people as a result of gender and racial discrimination in employment and pension acquisition. Ginn then goes on to examine the cultural and ideological factors 
underpinning this concrete manifestation of older people's social devaluation, pinpointing in her exploration the social devaluation of those not participating in production, of age (ageism), of femaleness (sexism) and of race/ethnicity (racism). Thus, amongst other things, women are held to be 'past it'. Ethnic minority older people suffer alternatively from over-intervention by social services or from underintervention, the latter a result of either the myth that families are always available to help or the failure of services to cater for differences in religion, language, dietary preferences and behavioural norms.

While feminists have succeeded in drawing attention to gendered inequalities in earnings, employment opportunities and domestic labour, the oppression of older women-particularly those from minority ethnic groups - has been less visible. Likewise, the position of carers tends to have been researched more than the experiences of those receiving care. And Ginn is not optimistic about the changes in community care arrangements which support privatisation at the expense of those with few resources.

Ginn concludes by arguing that the self-organisation of older people is crucial. She anticipates difficulties given the tendency of older people to align themselves politically on the basis of class rather than age. She also illustrates how, despite a recent proliferation of membership and involvement of women at all levels, compared with the United States, British 'grey' organisations still tend to neglect the issue of gender, at least in relation to structural inequalities. It is to be hoped that the European Year of Older People and Solidarity Between the Generations might go some way to raise general awareness of ageist, as well as associated sexist and racist, concerns and to boost the self-esteem of older people, thereby alerting them to the possibilities of collective action. Such steps are certainly necessary if older people are to be wholly involved in the definition of their needs and, subsequently, if services are to be targeted more efficiently.

\section{References}

Bebbington, A. C. and Davies, B. P. 1983 . Equity and efficiency in the allocation of personal social services, British Journal of Social Work, 12, 309-30.

Bowns, I., Challis, D. and Tong, M. S. 1991. Health checks on patients 75 years and over in Nottinghamshire after the new GP contract, British Medical Journal, 305, 6I9-62 I.

Institute of Health Studies,

University of Durham,

Durham 